\title{
La Consagración de la
}

\section{Catedral de Lima a través DE UNA RARA MEDAlla CONMEMORATIVA, 1625}

The Consecration of the Cathedral of Lima Through a rare

Commemorative Medal, 1625

Ricardo Álvarez-Carrasco ${ }^{1}$

Resumen

El objeto de la presente investigación es la descripción del devenir histórico de la Basílica Catedral Metropolitana de Lima durante sus primeros noventa años de existencia, entre 1535 y 1625, es decir desde su primera fundación hasta el acto de consagración, a propósito del hallazgo de una rara medalla que conmemoraba este último acto.

Palabras claves: Catedral, Lima, virreinato, Perú, numismática, siglo XVI.

\section{Abstract}

The purpose of the present investigation is the description of the historical evolution of the Metropolitan Cathedral Basilica of Lima during its first ninety years of existence, between 1535 and 1625 , that is, from its first foundation until the act of consecration, regarding the finding of a rare medal commemorating this last act.

Keywords: Lima, cathedral, viceroyalty, Peru, numismatics, 16th century.

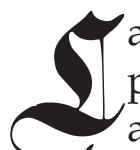

a Basílica Catedral de Lima es uno de los principales edificios de la ciudad, siendo además una de las construcciones más antiguas que existen hoy en día; sin embargo, $\mathrm{su}$ actual arquitectura es el producto final de un turbulento proceso que se extendió por muchos años.

1 Instituto Nacional Materno Perinatal, Lima. Asociación de Historia de la Medicina Peruana y Parques Conmemorativos. Prosecretario de la Academia Panamericana de Historia de la Medicina.
Primera Catedral (1535-1543)

La primitiva catedral fue establecida el lunes 18 de enero de 1535, el mismo día que se fundó la ciudad, cuando Francisco Pizarro le asignó un solar en la Plaza Mayor, al igual que a la casa de gobierno y el cabildo. Además, el conquistador mandó a trazar las calles que circundarían el centro original de la ciudad, zona que con el transcurrir de los años se denominaría el Damero de Pizarro. (1)

La fábrica de la primera iglesia fue decididamente estrecha y modesta, incluso el obispo de Panamá Tomás de Berlanga, con motivo de su visita a Lima, le reprochó a Pizarro tal situación, quien prometió remediarla prontamente pero la muerte le impidió cumplir su ofrecimiento. (1)

\section{Segunda Catedral (1543-1572)}

En 1543, al erigirse la sede episcopal de Lima, su primer obispo Jerónimo de Loayza ordenó la demolición de la iglesia erigida por Pizarro y en su lugar se construyó una más amplia y de mejor calidad, capaz de sustentar con mayor decencia su dignidad de catedral. (1) Este templo se terminó en 1551, bajo la advocación 
y patronazgo de San Juan Evangelista pero sus mejoras no agradaron a Loayza quien, secundado por el cabildo, el gobernador Lope García de Castro y los vecinos más notables de la ciudad, resolvió edificar una nueva iglesia que estuviera a la altura de las catedrales de España. (1)

\section{Tercera Catedral (1572-2020)}

En 1564, cuando el cabildo discutía la ubicación y orientación de la futura catedral, se nombró a Alonso Beltrán como maestro mayor encargado de construirla, quien levantó los planos ajustándose a las características de la Catedral Metropolitana de Sevilla, aunque con dimensiones menores (1). Sin embargo, su orientación espacial no se definió por largo tiempo, ya que los pareceres eran muy diversos, siendo el virrey Francisco de Toledo quien dispuso se construyera con dirección al oriente y que las casas arzobispales, que se habían de tomar para la obra, se edificaran en el sitio de la antigua cárcel, lugar que actualmente ocupa el Museo del Palacio Arzobispal.(2)

En 1572, Jerónimo de Loayza colocó la primera piedra de la tercera catedral aunque no llegó a verla concluida pues falleció en octubre de 1575. (2) El término del gobierno de Toledo constituyó un importante revés para el avance de las obras ya que sus sucesores carecieron de la resolución y el ingenio para continuarlas. (1) La falta de dinero no sólo paralizó la construcción, además las autoridades decidieron derribar todoloedificadoy reanudar los trabajos con los mismos fundamentos pero con materiales menos costosos, de tal suerte que la ejecución ofreciera menos dificultades, se hiciera más rápidamente y se tuviera la garantía de concluirla exitosamente. (1)

Al finalizar el gobierno del virrey García de Mendoza, todo lo avanzado se había demolido y sólo perduraban una parte de los cimientos a flor de tierra. (1) En 1596, cuando Luís de Velasco se hizo cargo del virreinato, se ordenó construir los muros y pilares con cal y ladrillo, sobre bases de cantería, con la suficiente solidez para soportar el peso de las bóvedas; las obras se reanudaron en 1598 y alcanzaron una rapidez inusitada bajo la atenta vigilancia del virrey. (1)

En 1604 estaba terminado alrededor de la mitad del edificio, ello permitió instalar un altar, donde el obispo Toribio de Mogrovejo celebró una misa por la fiesta de la Purificación de Nuestra Señora, el 2 de febrero de aquel año, evento que dejó muy satisfecho al virrey, cuyos desvelos se vieron coronados aunque sea parcialmente. (1). El conde de Monterrey, sucesor de Velasco, no puso mayor empeño en el asunto y los avances fueron muy modestos en aquel período (2); para colmo de males, en 1609, durante el gobierno del marqués de Montesclaros, Lima fue asolada por un sismo de gran intensidad, que produjo graves daños en el templo inconcluso, en particular en sus bóvedas. (1)

Luego de largas discusiones y varios dictámenes, se decidió derribar las bóvedas mayores y modificar parte de los planos para evitar que sucedieran averías semejantes en el futuro; sin embargo, ello no evitaría que la dañaran gravemente los terremotos de $1687 \mathrm{y}$ $1746(2,3)$. Los trabajos se reanudaron durante el gobierno del príncipe de Esquilache, en la época en que la sede arzobispal de Lima la ocupaba Bartolomé de Lobo Guerrero, y se ajustaron a lo dispuesto por el Supremo Consejo de las Indias; es decir, se fueron volteando los arcos y cerrando las bóvedas en crucería. (1)

En 1622 quedaron habilitadas la capilla y el retablo mayor, ubicándose el coro de los 
capitulares al principio de la nave central y, gracias a ello, el 15 de agosto de aquel año se celebró la Asunción de Nuestra Señora. (2) Al cabo de cincuenta años del inicio de la construcción del tercer edificio de la catedral, los vecinos de la ciudad al fin podían vislumbrar el término de la misma, aunque sólo de puertas para adentro porque las portadas y las torres aún estaban por edificarse. (1)

Poco después, Pedro de Noguera, un distinguido artífice catalán, comenzó a labrar la portada principal al estilo del renacimiento italiano, por entonces denominado toscano (2), y con ese propósito se adoptó los dibujos del maestro Juan Martínez de Arrona (3), y se empleó la piedra de Panamá como principal material. (1)

Noguera era natural de Barcelona, aunque fue en Sevilla donde se inició en la arquitectura y el tallado, en una época en la que aún se dejaba sentir el influjo de Pietro Torrigiano, notable émulo de Miguel Ángel. (4) Vino al Perú en los primeros años del siglo XVII, contrayendo matrimonio con la dama limeña Úrsula de Bonifaz, el 30 de diciembre de 1621, y luego de una fructífera labor artística falleció alrededor de 1655. (4)

El levantamiento de las torres se emprendió a continuación, alcanzando una altura de 120 pies castellanos -poco más de 33 metros-; sin embargo, resultaron defectuosas ya que no guardaban la debida proporción con su volumen. Domingo Angulo refiere que dicho desperfecto fue solucionado por los sismos que asolaron la ciudad, ya que sólo dejaron en pie sus bases que eran lo único que valía. (1)

El 20 de abril de 1625 hizo su entrada pública Gonzalo López de Ocampo, cuarto arzobispo de Lima (Figura 1), quien al conocer que nuestra catedral aún no estaba consagrada decidió cumplir con ese rito el domingo 19 de octubre de aquel año, en una ceremonia principió entre las siete y ocho de la mañana y duró hasta las cuatro y media de la tarde. $(1,3,5)$ Según Mendiburu, aquel día "se derramaron muchas monedas de plata que se acuñaron con las armas del Rey y de esta iglesia", aseveración con la que concuerda Palma, quien, a fines del siglo XIX, refería que "aún existen medallas de plata que se acuñaron para conmemorar el acto" , aunque no las describió. $(6,7)$

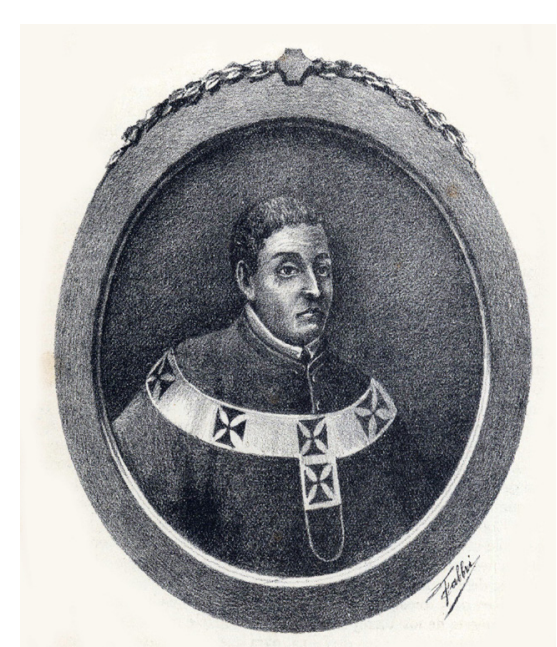

Figura 1. Gonzalo López de Ocampo, arzobispo de Lima, 1623 a 1626. Dibujo de Fabbri publicado en el libro Galería de retratos de los gobernadores y virreyes del Perú (1532-1824) de Domingo de Vivero y José Antonio Lavalle, Lima 1891.

Portal nos legó una extensa descripción de la ceremonia, basándose en una narración de la época:

"Al toque del alba, las campanas de las iglesias dieron la señal para que la nobleza saliese de sus casas, y los estruendos del cañón fueron recibidos por la música de viento. En el cementerio de la Catedral se veían dos magnificos solios destinados al Sr. Virrey y al Revdmo. Arzobispo, y estos los ocuparon a las seis de la mañana. Las puertas se hallaban cerradas y custodiadas por la tropa, para alejar el gran concurso". (8) 
"A la hora dicha, comenzaron las ceremonias, y el Iltmo. Sr. Arzobispo, después de bendecir el agua, comenzó a hisopear por la parte de afuera la iglesia y cementerio. Después de esto, tocó con el báculo la puerta principal tres veces, entonando el Attolite portas principes vestras, y le fue abierta por un señor canónigo que se había situado en el interior". (8)

"Entró su Iltma. con algunos ministros revestidos de capa magna, y comenzó la orquesta musical a entonar el himno Veni Creator Spiritus, y después las letanías. En el interior se habia esparcido del altar mayor al coro, en forma de cruz, ceniza interpolada con arena, en la que escribió ó dibujó el Sr. Arzobispo el abecedario griego, y después el latino". (8)

"Concluida esta operación, bendijo nuevamente agua con sal, vino y ceniza para la consagración del altar, que comenzó con el entonamiento del salmo Deus in adjutonum, dio varias vueltas a la iglesia, rociándola con la indicada agua, y después tomó el Santo Óleo del Crisma, y ungió las doce cruces que se habian puesto en las paredes del templo". (8)
"La conclusión de estas ceremonias fue anunciada a las dos de la tarde con un repique general y salva de artillería; abriéndose las puertas del templo para que entrasen el Virrey y el pueblo, con gran derroche de monedas, ostentando las armas de la Iglesia y las de Su Magestad Católica". ( 8)

El virrey mencionado en este relato es Diego Fernández de Córdova, primer marqués de Guadalcazar, quien había entrado en Lima el 25 de julio de 1622, gobernando por seis años, cinco meses y diecinueve días; y, finalmente, entregó el mando al conde de Chinchón, el 14 de enero de 1629. (5) Para comprender la importancia de esta ceremonia religiosa, se le debe situar en el contexto de una sociedad limeña aún pueblerina, eminentemente católica y cuya vida discurría en el oscurantismo. (9) Esto la convirtió en un hecho único y extraordinario que merecía procurarle el mayor realce y perennizarlo por los siglos de los siglos, y ello propició la existencia de medallas conmemorativas, tanto la referida por Mendiburu como la que es objeto de esta investigación. (6)

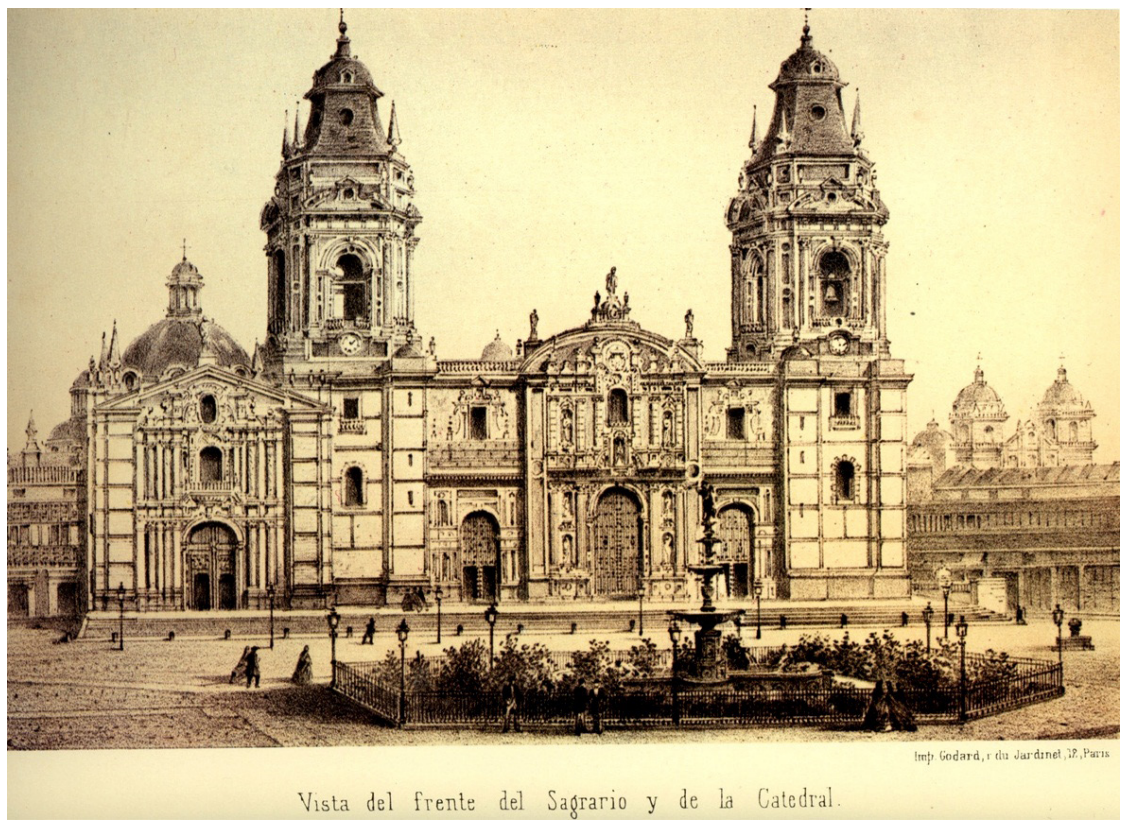

Figura 2. Catedral de Lima e iglesia del Sagrario, década de 1860. Grabado de Godard y Jardinet, París. 
La catedral se declaró concluida en 1649, veinticuatro años después de su consagración (figura 2); y, en 1924, al conmemorarse los 299 años de dicha consagración, fue elevada a la categoría de Basílica por el papa Benedicto XV. (8)

\section{La Medalla Por la Consagración De la Catedral De Lima}

Hace más de una década hallamos una medalla colonial peruana que databa del siglo XVII, que luego de prolijas investigaciones concluimos era muy rara, se trataba de una pieza que conmemoraba la consagración de la Catedral de Lima, el domingo 19 de octubre de 1625. Todos los numismáticos consultados desconocían su existencia y al inspeccionarla ninguno opinó contra su legitimidad; además, se adquirió en circunstancias en las que claramente no había afán de lucro, el comerciante que la poseía carecía de mayor conocimiento histórico y numismático pero consideramos indispensable continuar nuestra pesquisa documental en diversas fuentes bibliográficas.

El ejemplar tiene un aspecto físico e inscripciones que nos dan clara cuenta que se trata de un emprendimiento particular y que la hechura es artesanal, habiéndose grabado sus leyendas mediante un punzón (Figura 3). Tamayo define a las medallas artesanales como aquellas no acuñadas en la Casa de Moneda por medios mecánicos y que han sido trabajadas a mano. (10)

Antes de 1760 fue excepcional la fabricación de medallas en el Perú, ello no era exclusivo de este virreinato, la acuñación de ese tipo de ejemplares no se acostumbraba en España y sus colonias, incluso para hechos tan trascendentes como la ascensión al trono de los monarcas hispanos. (11)

La Real Casa de Moneda de Lima se había establecido el 21 de agosto de 1565 mediante la Real Cédula dictada por Felipe II, en la ciudad de Segovia (12,13), comenzando a funcionar en marzo de 1568 (14), en un solar adyacente al Palacio de los Virreyes (15). En 1574 se suspendió la acuñación en Lima, que se trasladó íntegramente a Potosí, reiniciándose en 1577, siendo nuevamente paralizada en 1592. (15)

Los escandalosos fraudes ocurridos en la Real Casa de Moneda de Potosí convencieron a

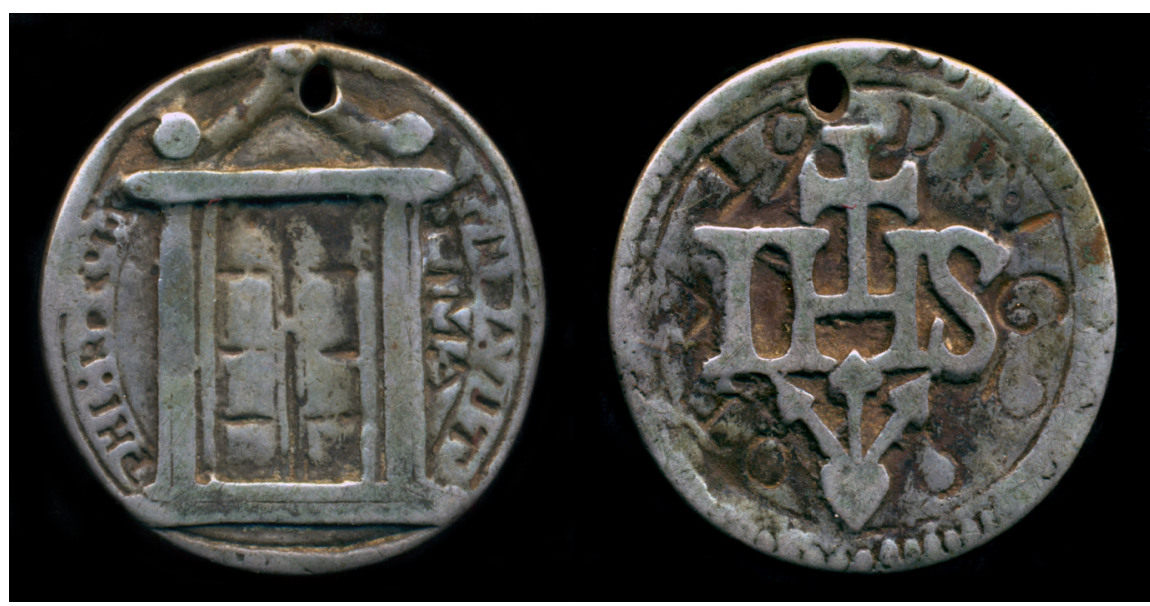

Figura 3. Anverso y reverso de la medalla por la consagración de la Catedral de Lima. Domingo, 19 de octubre de 1625. Colección personal. 
Carlos II para que emitiera una Real Cédula en 1683 que ordenó la reapertura definitiva de la ceca de Lima $(13,14,16)$.

En 1760, el virrey José Manso de Velasco, conde de Superunda, ordenó la acuñación de la primera medalla peruana que conmemoró la jura de fidelidad a un monarca hispano, en este caso la que se realizó en Lima en honor a Carlos III (17), que se fabricó con la máquina volante llamada San Andrés Apóstol, llegada en 1751 (18), y fue grabada por el artista mexicano José Rivero de Zúñiga, por entonces talla mayor de la ceca limeña. (16)

Entre las medallas que celebraron la jura de fidelidad a los reyes españoles hay dos ejemplos de hechura artesanal, la de Carlos IV en Paucartambo -1790- y la de Fernando VII en Arequipa -esta no contiene la fecha, pero está documentado que la ceremonia se llevó a cabo en 1809. $(10,19)$ Las medallas coloniales sobre temas diferentes a la exaltación de tales monarcas se pueden considerar raras, y aquellas fabricadas por fuera de la ceca limeña aún más exóticas.

La medalla objeto de esta investigación es de plata aunque no hemos definido su ley en fino, tiene un diámetro de 27 milímetros, un peso de 5,7 gramos, el cospel posee un espesor de alrededor de 1 milímetro, los bordes son algo irregulares, y el canto es liso. Carece de una marca o inicial que identifique a su grabador, y presenta un orificio de aproximadamente 2 milímetros de diámetro, practicado en forma artesanal, seguramente con el propósito de colgarla al cuello.

Tiene estampada en el centro del anverso, una puerta de dos hojas, que suponemos es la principal de la Catedral de Lima, la cual está rodeada por la inscripción latina, incusa y semicircular "PHI:REX IV" -Rey Felipe IV- a la izquierda, y a la derecha "FUNDAVIT LIMA" -Fundada en Lima-. Esta leyenda denota que al momento de la consagración catedralicia, el rey de España era Felipe IV (n.1605-m.1665), quien ascendió al trono el 31 de marzo de 1621, cuando apenas tenía 16 años, y reinó por más de cuatro décadas, falleciendo de disentería a los 60 años de edad. (5)

El centro del reverso está dominado por la inscripción "IHS", epígrafe formado por letras entrelazadas que originalmente abreviaban el nombre de Jesucristo, a las que posteriormente se dio el significado Iesus Hominum Salvator -Jesús salvador de la humanidad-. De la letra central del epígrafe emerge una cruz, y debajo de este conjunto aparece un pequeño corazón del cual surgen tres saetas con las puntas hacia arriba, esta alegoría está rodeada por la inscripción incusa circular "OTU 19 DE 1625" -Octubre 19 de 1625 -.

Es evidente que esta medalla no es la descrita por Mendiburu, quien afirma que aquel día se repartieron unos ejemplares acuñados "con las armas del Rey y de esta iglesia". (6) Por su parte San Cristóbal manifiesta: "Alguna vez fue el que estas noticias historiales redactan poseedor de una de las medallas de plata que se acuñaran, conmemorativas de la magnífica fiesta. El disco de la medalla era el de medio duro" ; sin embargo, no abunda en su descripción. (20)

El epígrafe del reverso originalmente fue adoptado por el religioso francés San Bernardo de Claraval (n.1090-m.1153), como representación de la divinidad en sí mismo, más tarde lo utilizó Juan Colombini (n.1304-m.1367), aristócrata italiano, quien fundó la congregación de los clérigos apostólicos de San Jerónimo y luego de su muerte fue beatificado por Gregorio XIII. 
En 1541, San Ignacio de Loyola (n.1491-m.1556) acogió este monograma en su sello de superior de la Compañía de Jesús, convirtiéndolo en el emblema de los jesuitas, orden religiosa aprobada por el papa Paulo III mediante la bula del 27 de setiembre de 1540, que luego llegaría al virreinato del Perú bajo el gobierno de San Francisco de Borja, su tercer Superior General, desembarcando en el puerto del Callao el 28 de marzo de 1568 con la misión de fundar la primera provincia jesuítica en territorio hispanoamericano $(21,22)$.

Por ello estimamos que el monograma del reverso de la medalla corresponde a la Compañía de Jesús y por tanto es muy probable que haya pertenecido a uno de sus miembros en el Perú, confeccionándose una por una, en un número indeterminado, durante la época de la consagración de la Catedral de Lima. Por entonces era una práctica común entre los sacerdotes, llevar consigo medallas de carácter religioso no conmemorativo, fabricadas en España u otros países europeos, las cuales eran tomadas entre las manos o besadas durante los rezos y otros ritos cristianos. En este caso lo insólito era el carácter conmemorativo del ejemplar que hemos descrito.

Aunque los jesuitas alcanzaron gran influencia, poder y riqueza en las colonias hispanas de América, serían acusados de incitar el tumulto popular sucedido en Madrid en 1766, y de pretender convertir al Paraguay en un reino independiente de la Corona, por lo que Carlos III ordenó su expulsión mediante la pragmática del 2 de abril de 1767 que se comunicó sigilosamente a los virreyes y capitanes generales de sus colonias, quienes la ejecutaron casi simultáneamente tiempo después. (21)

La consagración de la Catedral de Lima fue la última actividad relevante del arzobispo
López de Ocampo, quien poco después partió en visita pastoral rumbo al norte del virreinato, falleciendo inesperadamente en el pueblo de Recuay, en la provincia de Huaylas, a la medianoche del miércoles 16 de diciembre de 1626. (23) Según Mendiburu, al parecer fue asesinado por un cacique de la zona en venganza porque el prelado lo había separado de su concubina. (6) Se le enterró el lunes 21 en el pavimento del altar mayor de la iglesia de aquel lugar. (23)

\section{EPÍlOGO}

El hallazgo de una rara medalla colonial peruana del siglo XVII despertó el interés por conocer las primeras décadas de la turbulenta existencia de la Catedral de Lima, ello implica que el descubrimiento de otros ejemplares virreinales puede constituir una fuente de información inédita y un gran estímulo para investigar otros hechos olvidados para la gran mayoría de peruanos, y que sólo están a la espera que los estudiosos los descubran.

\section{ReFERENCIAS BibLIOGRÁficAs}

1. Angulo D. La Metropolitana de Lima. En: Lima Precolombina Y Virreinal. Lima: Artes Gráficas - Tipografía Peruana S.A; 1938:173-180.

2. Tamayo A. José María Fernández de Soto, Talla Mayor de la Real Casa de Moneda de Lima. Numismática. 1980;(31):2-20.

3. San Cristóbal A. Arquitectura virreinal religiosa de Lima, Lima: Universidad Católica Sedes Sapientiae; 2011:77,79,322,468.

4. Vargas R. Ensayo de un diccionario de artífices de la América Meridional. 2da. edición. Burgos, España: Imprenta de Aldecoa; 1968:289-292.

5. Mendiburu M. Diccionario Histórico Biográfico del Perú. Tomo III. Lima: Imprenta J. Francisco Solís; 1878:238,248,253.

6. Mendiburu M. Diccionario Histórico Biográfico del Perú. Tomo VI. Lima: Imprenta Bolognesi; 1885:98,99,100,101.

7. Palma R. De potencia a potencia. Crónica de la época del decimotercer virrey del Perú. En: Tradiciones Peruanas I. Narrativa 156. Barcelona: Lingua Narrativa; 2010:186.

8. Portal I. Lima Religiosa. Lima: Imprenta Gil S.A.; 1925:47-52.

9. Barreda F. Vida Intelectual Del Virreinato Del Perú. 3ra. edición. Lima: Imprenta de la Universidad Mayor de San Marcos; 1964:192-195.

10. Tamayo A. Las medallas artesanales en la numismática peruana. Numismática. 1988; (38):23-25.

11. Medina J. Medallas coloniales hispano-americanas. Santiago 
de Chile: Imprenta en la Casa del Autor; 1890:11-13.

12. De Aliaga L. Historia de la acuñación de monedas y medallas en el Perú. Numismática. 1965; (4):19-24.

13. De Haro D. Fuentes documentales e historia monetaria. La Casa de Moneda de Lima. En: Archivo General de la Nación - Archivo Colonial (1717-1829). Pontificia Universidad Católica del Perú. Lima: Instituto Riva Agüero; 2014: 26-27.

14. Camprubí C. Casa Nacional de Moneda. IV Centenario (15651965). Numismática. 1981; (32):87-116.

15. Callirgos A, Pin F, Rocca J. Casa Nacional de Moneda, 450 Años acuñando historia. Moneda. 2015; (163):4-6.

16. Álvarez R. Superintendentes, administradores, ensayadores y grabadores en las cecas del Perú Virreinal. Hécate. 2019; (6):204224.

17. Goepfert A, De La Puente P. Medallas del Perú. Banco Central de Reserva del Perú. Lima: Rapimagen S.A.; 2015: 7.

18. Salazar S. Lima, Su moneda y su ceca. Numismática. 1981; (32):117-142.
19. Medina J. Medallas De proclamaciones y juras de los reyes de España en América. Santiago De Chile: Imprenta en la Casa Del Autor; 1917. pp.1,2,72,167-169,213,214.

20. San Cristóbal A. La transformación de la Catedral de Lima (1896-1898). Bira. 1992; (19):133-166.

21. Cortada J. Historia de España desde los tiempos más remotos hasta 1839. Tomo III. Barcelona: Imprenta de A. Brusi; 1842: 264.

22. Albó X. Jesuitas y Culturas Indígenas. Perú 1568-1606. Su Actitud. Métodos y Criterios de Aculturación. 1ra. Parte. América Indígena. 1966; 26(3): 251-445.

23. Bermúdez J. Anales De la Catedral de Lima 1534-1824. Biblioteca Virtual Universal, Buenos Aires (Internet). 2003. (Citado el 11 de enero de 2020). URL disponible en: http:// www.biblioteca.org.ar/libros/70680.pdf

\section{CORRESPONDENCIA: \\ ralvarezcarrasco@yahoo.com}

FECHA DE RECEPCIÓN: 14-01-2020.

FECHA DE ACEPTACIÓN: 20-02-2020. 